Article

\title{
Revisiting the Indus Basin Model for an Energy Sustainable Pakistan
}

\author{
Abrar Hashmi ${ }^{1, *(\mathbb{D}}$, Aamer Iqbal Bhatti ${ }^{1}$, Saira Ahmed ${ }^{2}$ (D) Muhammad Atiq Ur Rehman Tariq ${ }^{3,4}$ (D) \\ and Andre Savitsky 5
}

Citation: Hashmi, A.; Bhatti, A.I.; Ahmed, S.; Tariq, M.A.U.R.; Savitsky, A. Revisiting the Indus Basin Model for an Energy Sustainable Pakistan. Water 2022, 14, 702. https://doi.org/ $10.3390 / w 14050702$

Academic Editor: Aizhong Ye

Received: 20 January 2022

Accepted: 18 February 2022

Published: 23 February 2022

Publisher's Note: MDPI stays neutral with regard to jurisdictional claims in published maps and institutional affiliations.

Copyright: (C) 2022 by the authors. Licensee MDPI, Basel, Switzerland. This article is an open access article distributed under the terms and conditions of the Creative Commons Attribution (CC BY) license (https:// creativecommons.org/licenses/by/ $4.0 /)$.
1 Department of Electrical Engineering, Capital University and Technology, Islamabad 45750, Pakistan; aib@cust.edu.pk

2 Directorate of Sustainability \& Environment, Capital University and Technology, Islamabad 45750, Pakistan; dr.saira@cust.edu.pk

3 College of Engineering and Science, Victoria University, Melbourne 8001, Australia; atiq.tariq@yahoo.com

4 Institute for Sustainable Industries \& Liveable Cities, Victoria University, P.O. Box 14428, Melbourne 8001, Australia

$5 \quad$ UZGIP Institute, Tashkent 100021, Uzbekistan; andresavit@yandex.ru

* Correspondence: abrarhashmi313@gmail.com

\begin{abstract}
Water is vital and an essential entity directly and indirectly for all living creatures from their birth, whereas electrical energy has a dominant role in the growth of society in general and for human beings in particular. Optimal use of water and production of electrical energy at minimum cost are potential research challenges. Hydraulic energy is one of the cheapest and the most exploited renewable energy resource for power generation worldwide, and is in line with the seventh United Nations Sustainable Development Goal (SDG 7). The Indus basin is a trans-boundary basin, and its modeling has been a source of interest for scientists and policymakers. Indus Basin Model Revised (IBMR) has many variants, all focusing on optimal use of water for irrigation purposes. In this paper, the modified IBMR model is proposed addressing both agriculture and power generation aspects simultaneously. This model optimizes the Consumer Producer Surplus (CPS) by considering different water inflow probabilities. A parameter has been introduced in the modified objective function to manipulate the supply of water to agriculture and hydropower generation. The proposed model has been implemented in Generic Algebraic Modeling System (GAMS) and case studies have been investigated in presence and absence of power generation. The results obtained show that, with incorporation of hydropower, basin wide income is increased up to $11.83 \%$ using $50 \%$ exceedance probability, and results are in agreement with reference power generation estimated by National Transmission and Dispatch Company (NTDC). The SDG 7 targets ensure the reasonable, dependable, sustainable and contemporary energy access to all. The current research is focusing on how Pakistan would achieve the SDG 7 targets. By 2040, it is anticipated that Pakistan's energy mix will have around $40 \%$ of hydropower and $16 \%$ of renewable energy.
\end{abstract}

Keywords: IBMR; GAMS; hydro-electric power; Indus basin; Million Acre Feet (MAF); Integrated Water Resources Management (IWRM)

\section{Introduction}

The world has seen a surge in the construction of hydropower dams in recent decades. At least 3700 big dams, each with an installed hydroelectric capacity of more than $1 \mathrm{MW}$, are now planned or under construction, mostly in developing nations. For example, 8507 dams are planned in Europe, with 278 now under construction, primarily in the Balkans [1]. Because of its high altitudes in the upper Indus region and abundant water, the Indus basin has a large hydropower potential to be developed. It is extremely difficult to use water efficiently because the region continues to face one of the world's most significant water management challenges of water storage infrastructure, or inefficient water use as a result 
of water losses in obsolete irrigation systems [2]. Nearly 2000 TWh of theoretical potential available annually in the upper Indus can be deceiving because the vast majority of it is technically and economically unviable. When we account for the various sustainability constraints that vary spatially, the potential becomes even lower [3]. The Indus basin is a trans-boundary and the most vulnerable basin shared by Pakistan, India, Afghanistan and China, causing considerable hydro-political tensions [4]. Integrated approaches are required to achieve Sustainable Development Goals (SDGs) for water, energy and food requirements for the Indus basin [5]. The global warming in the region is also a big threat towards water and food security. The upper Indus basin exhibits that the global pace of warming as the region is expected to reach the $1.5^{\circ} \mathrm{C}$ and $2.0^{\circ} \mathrm{C}$ thresholds almost a decade earlier than the corresponding warming at the global scale [6].

Indus basin is a trans-boundary basin unique composition. Its total area is about $1,120,000 \mathrm{~km}^{2}$, which constitutes about $54 \%$ of the Southeast Asia. It runs through four countries Pakistan, India, China and Afghanistan with an area of 520,000, 440,000, 88,000 and $72,000 \mathrm{~km}^{2}$, respectively. Pakistan and India are using $60 \%$ and $25 \%$ water of the Indus basin, respectively [7]. In order to use this water judiciously, both countries signed "The Indus Waster Treaty" in 1960 [8]. Under this treaty, India gained control of the Beas, Ravi, and Sutlej rivers, while Pakistan gained control of the Indus, Chenab, and Jhelum rivers. The water distribution amongst provinces in Pakistan is according to Provincial Water Accord 1991 [9]. In Pakistan, there is a broad agribusiness and water system framework, alluded to as the Indus Basin Irrigation System (IBIS). This is the biggest bordering water system framework on the planet. The normal yearly stream of the Indus bowl is around 146 MAF. It has two noteworthy capacity repositories, specifically Mangla and Tarbela. It consists of 19 barrages, 12 interface canals, and 45 noteworthy canal commands. The aggregate length of canals is around $60,000 \mathrm{~km}$ and around 120,000 watercourses to irrigate farms. It inundates 16.2 million hectare and contributes about $25 \%$ of Gross Domestic Product (GDP). It wins about $70 \%$ of the export income and utilizes $50 \%$ of the workforce straightforwardly and another $20 \%$ in a roundabout way [10].

The study of the Indus Basin of Pakistan carries a long legacy of planning and research. In order to manage the Indus Basin River System (IBRS), the work on the Indus Basin Model started in 1976 by the World Bank and the Water and Power Development Authority (WAPDA) jointly with a view to address the water dependent economy of Pakistan. The preliminary work on Indus Basin Model by Johannes Bisschop et al. [11] proposed a high level Indus Basin Model based on linear programming. The goal was to maximize the overall basin income aggregating the individual fifty-three polygons income using multi-level programming [12]. Instead of presenting mathematical details of IBMR, the author focused on the multi-decision-making aspect of model and posed it as a hierarchical decision-making problem.

The work on the Indus Basin Model (IBM) started by O'Mara et al. [13]. This paper comprehensively describes the Indus Basin Model (IBM) family, structure, model validation and simulation results to access the conjunctive use in the Indus irrigation system for alternative policies (Figure 1). Alexander Meeraus and Masood Ahmad launched an Agricultural Impact Study (AIS) [14] in September 1985 to assess the impact of the Kalabagh Dam on Pakistan's Agriculture sector and the first draft of the report was completed in July 1986. In this report, the Indus Basin Model using linear programming was used with computer implementation in the FORTRAN language to run on a main frame computer environment. This first version focused on farm level water distribution, and income assessment. Later on, all other versions were developed in GAMS [10,15] and used for the management of water resources distribution in different polygons, crops production, demand and supply of provinces, livestock, etc. The subsequent refined version is called the Indus Basin Model Revised (IBMR), jointly developed WAPDA of Pakistan and World Bank Development Research Center for Water [16]. In IBMR, the mathematical complexities were simplified by reducing the number of equations, constraints, and, at the same time, 
replacing polygons into Agro Climatic Zones (ACZ). The whole country has been divided into 12 ACZ zones 5 in Punjab, 4 in Sindh, 2 in Khyper Pakhtunkhwa and 1 in Baluchistan.

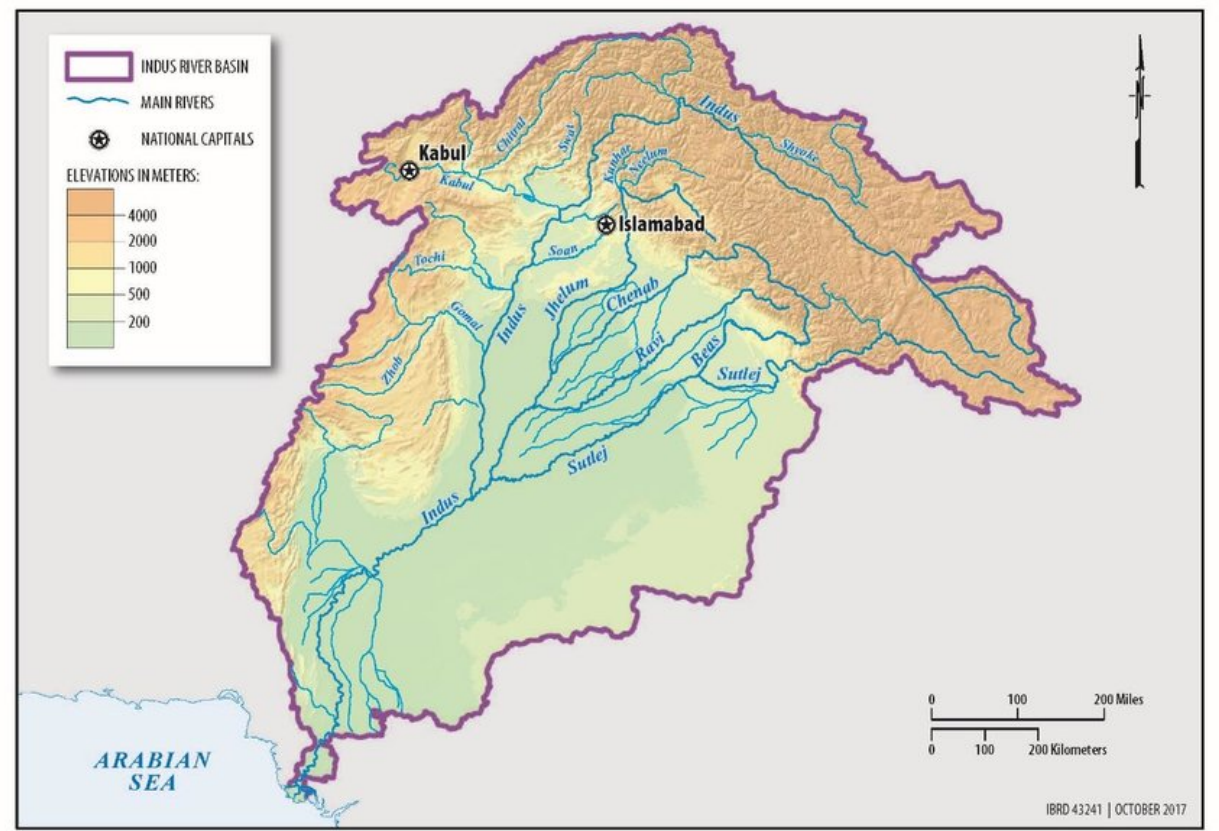

Figure 1. The Indus Basin of Pakistan [17].

The Indus Water System can be categorized in three eras, namely Pre Indus Water Treaty (1947-1960) period; Post Indus Water Treaty (1960-1975); and the Management era (1975-2000). It describes a half century perspective on management of the Indus basin focusing crisis planning, multi strategies planning to achieve governance goals, plantation at multiple topographical levels for water management, regional water management to variation patterns and scientific planning to explore alternatives [18]. The Indus River System Model (IRSM) was developed in parallel to the Indus Basin Model and is used as a planning tool for water management options in Pakistan. This model is discussed in the report published in 14 August 2018 and jointly prepared by the Commonwealth Scientific and Industrial Research Organization (CSIRO) Australia and the Sustainable Development Policy Institute (SDPI) Pakistan. The project was funded by the Australian Government and supported by the Government of Pakistan. The main purpose of the project was to build capacity and knowledge management in water resources management with the prime focus on Integrated Water Resources Management [19].

\subsection{The Indus Basin and Hydro-Electric Power}

Indus River also plays an important role in hydropower generation of Pakistan. The total existing installed power capacity by all means as of March 2017 was about 29,945 MW, thermal being the largest share $(68.4 \%$ of capacity), hydro stands at second position $(23.8 \%)$, renewable about $4.1 \%$, and a small share of nuclear power plants approximately $3.6 \%$ [20]. The generated power at any specific time is considerably underneath the available generation capacity and shows up at its trough all through the winter when low water levels decline the hydropower yield. Pakistan has a huge hydropower potential of 60,000 MW and currently only about $8300 \mathrm{MW}$ of power is being generated as per Energy Book of 2018. Therefore, there is a considerable room for expansion in the area. According to Pakistan's 2040 indicative generation mix, hydropower would take the largest share of about $40 \%$ of total generation [21]. The results obtained from research reflect that, by 2040, the share of renewable and hydropower is expected to be about $16 \%$ and $40 \%$ of the total generation mix of Pakistan, respectively. To increase reliance on wind and solar energy, the government started the Jhimpir wind station in Karachi and Quaid-e-Azam Solar Park, 
in Bahawalpur [22,23]. Tarbela and the Mangla are the two major hydroelectric power stations using water spared from agriculture needs. These power stations coordinate with thermal generations for minimum cost of production of electrical energy subject to the satisfaction of constraints.

The prosperity index of a country is gauged by its per capita energy consumption. The world's average per capita energy consumption is about $2516 \mathrm{kWh}$, which is six times higher than Pakistan's consumption. In 2008, the reported shortfall was 4500 MW, which is $40 \%$ of the demand. The reason behind this gap is depletion of local reserves of oil and gas. The country has a huge estimated potential of $42 \mathrm{GW}$ hydropower, out of which only 6.5 GW has been exploited so far [24]. The period of 1975-2010 exhibits a log-linear relationship between electricity production and economic growth. On the basis of a lot of research in the power sector, Pakistan has a huge potential for hydropower. Based on this fact, hydropower plants are beneficial for two reasons. First, they produce clean energy. Second, the production cost would also decrease, resulting in lower tariff rates [25]. Pakistan has a unique natural resources distribution as compared to developed countries. These resources include solar energy, wind energy, coal and hydropower [26-29].

The IBMR purely deals with optimal utilization of water for irrigation needs only. However, it cannot handle the optimal use of water for both agriculture and power generation requirements. This paper presents a hybrid IBMR model addressing optimal utilization of water for both agriculture and power generation needs. The philosophy of this model is that it maximizes the CPS considering the exceedance probabilities for inflows subject to the satisfaction of constraints. The objective function has been modified by incorporating control parameter alpha $\alpha$ and integrating the energy cost of hydropower generation. The proposed model is implemented in GAMS and has been tested for scenarios with and without hydropower generation. The rest of the paper is organized as follows: Section 2 covers the literature. Section 3 is dedicated to the system modeling. Section 4 explains methodology. Section 5 elaborates the case studies, economic analysis of the proposed system and related discussions. Section 6 concludes the study and finally Section 7 discusses a few ideas for future work.

\subsection{Contributions}

The summary of main contributions to the paper is given below:

1. The main objective function of the IBMR is modified and the impact of hydropower generation is incorporated in CPS calculation.

2. A control parameter $\alpha$ has been introduced to control the water allocation for agriculture and power sector.

3. Mapping of the proposed model in GAMS to run on Dell Latitude Core i7 laptop with $7820 \mathrm{HQ} 2.9 \mathrm{GHz}$ processor and $16 \mathrm{~GB}$ of RAM in order to obtain results: CPS calculation and optimized energy generation mix for year 2040 and yearly energy generation up to 2040 .

\section{Literature Review}

River basins are the planet's hydrological units, and they play a crucial role in the planet's natural functioning. These are the backbone of agriculture and have a lion share towards economy. There are 263 river basins in the world ranging from small, medium to large [30]. Lakshmi et al. [31] discussed the 10 major basins namely Amazon, California, Colorado, Congo, Danube, Ganga Brahmaputa, Mekong, Mississippi, Murray-Darling, Nile and Yangtze in the context of precipitation, vegetation, evapotranspiration, total water, soil moisture and runoff with reference to their variations and impacts on the basins economy. The basin model is used to represent the relevant processes in a river basin, predicts the behavior of the basin under different circumstances or management scenarios and helps decision-makers to make rational water allocation among various users and sectors. The key issues for river basins users include water resources allocation, maintaining water quality, and rapidly growing demand [32,33]. 
Dhaubanjar et al. [34] provides the first theoretical framework that can assess the sustainable hydropower potential of the Indus basin. The selection of the Indus basin for this study is due to its high theoretical potential that combines with transboundary water issues, socio economic challenges, landscape vulnerability and high-water demand. For this study, hydropower potential is classified into four main classes, which is theoretical potential, technical potential, economic potential and sustainable exploitable potential (sustainably achievable potential that links hydropower with other SDGs). This framework is developed based on three main factors. Firstly, it incorporates the tools related to the hydropower development and associated SDGs that are available in the literature. Secondly, it incorporates local consideration of hydropower design. Thirdly, it includes thirty novel datasets to parameterize real world constraints like natural, legal, disaster and social constraints into mathematical models. This framework evaluates the hydropower potential at a basin scale considering two runs of river hydropower configurations. It is useful in combining the SDG 7 (energy) with S (food and water).

Hairaan et al. [35] conducted a detailed critical review of the literature related to the basin of some important rivers of southeast Asia. This study assesses the current status of environmental flow and river sustainability of Mekong River, Brahmaputra River, Citarum River and Muda River. The data are extracted from the literature related to the river hydrology, water quality, river alteration and restoration variables, which are then correlated for the assessment. Based on this study, it is concluded that, due to unsustainable utilization of the resources, stream flow of rivers is degrading with respect to both quantity and quality. Therefore, environmental flow assessment is a demanding approach of the time to attain river sustainability.

Shirast et al. [36] studied the effect of ten climate change scenarios on water availability and hydropower production of two contrasting small hydropower plants (SHP) in the upper Beas basin in the 21st century. The WEAP (Water Evaluation and Planning) model is used to combine cryosphere hydrology and hydropower production for this study. Simulated streamflow shows a complex relationship between hydrological response and future climate with uncertainties. The study shows that large flow hydropower plants are more sensitive to climate change than SHPs, and these have low flow and large heads. The assessment of glacio- hydrological changes and their impact on the power production using this framework is helpful in the planning of SHPs in the Himalayan region. Grover et al. [37] studied the impact of temperature and precipitation on hydrological factors that include discharge, ice melt, snow contribution and seasonal discharge in the high altitude scarcely gauged Chenab basin. The impact of major climatic variables on hydrological processes are quantified using biased corrected GCM (General Circulation Models) coupled with the HBV hydrological model for Chenab River. The study shows that climate change factors under RCP 8.5 and RCP 4.5 will increase the discharge throughout the century. A shift in annual discharge pattern is also observed. Furthermore, temperature increase will enhance snow meltdown, which would result in further increase of the flow of Chenab River. This whole scenario would affect basin water management, irrigation, storage and hydropower plants.

The Water Resources Management in South Asia is important with reference to present and future scenarios. Some important facts related to regional per capita water availability, population growth vs. per capita water availability, decreasing live storage capacity of reservoirs and province wise soil salinity status have been discussed. Mathematical Modeling of the Upper-Indus Glaciers and governing equation are discussed [38]. Pakistan's water profile has shifted dramatically, from one of abundance to one of scarcity. Per capita water availability decreased from $2172 \mathrm{~m}^{3}$ per tenant to $1306 \mathrm{~m}^{3}$ per occupant between 1990 and 2015. Pakistan takes out 74.3\% of its freshwater yearly, subsequently applying gigantic weight on inexhaustible water resources [39].

Assessments of global water bargains recommend that riparian states are not paying attention to the counsel to receive Integrated Water Resources Management (IWRM). Speculations propose that the bigger the quantity of arranging states, the lower the expense 
(per condition) of the joint activity of arrangements, yet the higher the exchange expenses of arranging and looking after them. The model exchanges between advantages and expenses related to the quantity of bargain signatories and apply it to a worldwide settlement informational index. Discoveries affirm that the exchange expenses of arrangement and the economies of scale are significant in deciding the scarcity of bowl wide understandings, the bargains' substance, and their degree [40].

"Pakistan's Water Economy: Running Dry", a notable study [41] by the World Bank received global attention on the Indus Basin Water Resources issues. In the recent past, the WAPDA and the World Bank analyzed to update the IBMR with reference to climate change impact on the Indus Basin. In [42], Yang et al. analyze the impact of climate change in the Indus Basin. The author studied the impact of climate changes in the basin. They also worked on Indus Basin Model Revision after 1992, and the revised version is known as Indus Basin Model Revised 2012 (IBMR-2012). IBMR-2012 was used to explore the impact of climate change for food security and water allocation in the Indus Basin. Hydro-climatic parameters' sensitivity analysis for the provinces showed that Punjab would be impacted with the least climate change in the future, whereas Sindh would suffer the most. According to the World Bank's 2020-2021 report, Pakistan may face a severe food shortage in the near future. The water shortage will increase to $32 \%$ by 2025 , resulting in a food deficiency of nearly 70 million tonnes [43].

In 2015, the UN conceived the 2030 Agenda for Sustainable Development Goals [44]. The government of Pakistan adopted Sustainable Development Goals (SDGs) through National Assembly Resolution in 2016 and became the first country in the world to do so. The national and provincial assemblies of the country formed specific task forces for implantation of SDGs. These steps are the reflection of national commitment to the SDGs. The national commitment to these priorities favors the 2030 Agenda. Pakistan is a fortunate country having 60,000 MW potential sites for hydropower generation. Tarbela and the Mangla are the two major hydroelectric power stations using water spared from agriculture needs. These power stations coordinate with thermal generations for the minimum cost of production of electrical energy subject to the satisfaction of constraints.

Pakistan wants to reduce its reliance on imported resources over the next five years. To direct the sector towards sustainability, it will steadily and significantly increase the share of indigenous, renewable resources in the nation's energy generation mix. A newly developed road map for a competitive power market will also be introduced. The Punjab government has planned to solarize 20,000 campuses, with an emphasis on rural areas. Solar panels will be installed in 10,800 schools in South Punjab as part of the first step of the "Ujala" initiative. The 'energy benchmarking' of public buildings is currently underway, with the goal of facilitating energy conservation, solar energy conversion, and energy efficiency improvements. The Sustainable Energy for All (SE4All) initiative aims to provide universal access to energy, while doubling the pace of energy quality change and increasing the share of renewable energy in the generation mix. Through the consultative process, a related National Action Plan 2018-2030 was finalized and released in 2019 [45].

\section{System Modeling}

IBMR is an hydro economic model jointly developed by the World Bank and WAPDA. It has many inputs and outputs related to water distribution and agricultural yields. The main objective function of IBMR is Consumer Producer Surplus (CPS), which is an indicator of basin-wide income. The Model is implemented in GAMS language and based upon the GRG optimization method. In this paper, we have used nonlinear demand and supply for IBMR. The objective function of IBMR-2012 does not account for the hydropower contribution in CPS. In the current paper, hydropower contribution is also incorporated in CPS calculation. A control parameter $\alpha$ has been introduced in the newly proposed objective function to control the multi-sectoral water distribution.

The operational conceptual model of IBMR is shown in Figure 2 indicating the standard inputs/outputs. 


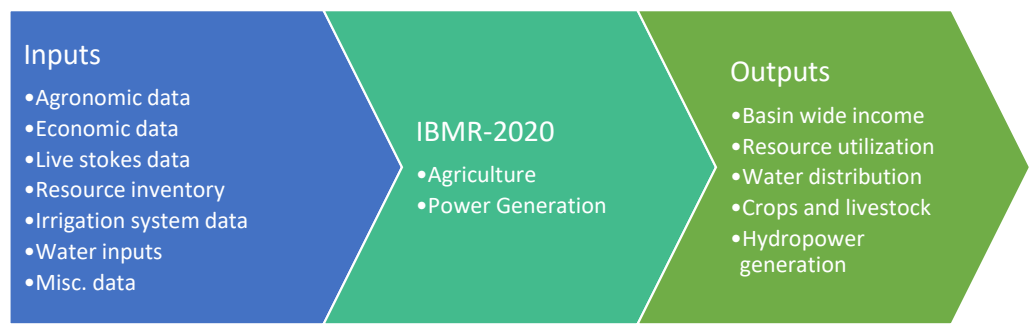

Figure 2. Conceptual model of IBMR.

\subsection{Objective Function}

The Consumer Producer Surplus (CPS) [42] calculates the basin-wide income in the following way:

$$
\begin{array}{r}
\text { CPS }=\sum \text { Price } * \text { Production }+\sum \text { WaterValue }+ \\
\sum \text { Export }-\sum \text { Cost }-\sum \text { Import } \\
- \text { Slackvariables }
\end{array}
$$

In the objective function, the Slackvariables reflect a penalty for not having enough water in the network flow model or not having enough produce to meet on-farm consumption. In actuality, there is an insufficient supply of irrigation water, output does not necessarily halt. As a result, this variable prevents infeasibilities under low-flow conditions and imposes constraints.This also implies that the objective value may not accurately reflect the true basin-wide net economic profits that would be observed in the event of a water shortage.

The newly proposed objective function includes energy costs that are given below:

$$
\begin{array}{r}
\text { CPS }=\sum \text { Price } * \text { Production }+\sum \text { WaterValue }+ \\
\sum \text { Export }+\sum \text { UnitPrice } * \text { EnergyProduced } \\
-\sum \text { Cost }-\sum \text { Import } \\
- \text { Slackvariables }
\end{array}
$$

This newly proposed objective function includes energy costs, and the control parameter is given below:

$$
\begin{array}{r}
\text { CPS }=\alpha\left(\sum_{Z} \sum_{G} \sum_{C} \text { Price }_{Z, c} * \text { Production }_{Z, G, C}\right. \\
\left.+\sum_{M} \sum_{N} \text { WaterValue }_{M, N}+\sum_{Z} \sum_{C} \text { Export }_{Z, C}\right) \\
+(1-\alpha) \sum_{M} \sum_{N}{\text { UnitPrice } * \text { Energy }_{\text {Produced }}, \mathrm{M}, N} \\
-\sum_{Z} \sum_{G} \text { Cost }_{Z, G}-\sum_{Z} \sum_{C} \text { Import }_{Z, C} \\
- \text { Slackvariables }_{\text {Slate }}
\end{array}
$$

where $Z$ is the Agro Climatic Zone (ACZ) index, $G$ is the groundwater type index, $C$ is the crop index, $M$ is the month index, and $N$ is the node or reservoir index. The control $\alpha$ is a control parameter, and it varies from 0 to 1 . Zero means all water is utilized for hydropower generation, whereas one shows that all water is allocated for agricultural purposes.

\subsection{Cost Function}

The basin wide cost [42] includes the cost of seed, tube well operating cost, fertilizer cost, protein cost, labor cost and misc costs, and it is given by: 


$$
\begin{array}{r}
\text { Cost }_{Z, G}=\text { Miscct }_{Z, C, S, M}+\text { SeedP }_{Z, C, S, M} \\
+ \text { TW }_{Z, C, S, M}+\sum_{Z} \sum_{C} \sum_{S} \sum_{W}\left(\text { Fert }_{Z, C, S, M}+\right. \\
\text { Tractor } \left._{Z, C, S, M}\right)+\sum_{Z} \sum_{G} \sum_{A} \text { Animal }_{Z, G, A}+ \\
\sum_{Z} \sum_{S E A} P P_{Z, S E A}+\sum_{Z} \sum_{G} \sum_{M} \text { Labor }_{Z, G, M}
\end{array}
$$

where $S E A$ is the season index (rabi and kharif). $W$ is the water application index (for example, standard, mild, or high stress, where stress application uses less water and labor and yields less production). $S$ is the cropping sequence index (e.g., standard, late, or early planting).

\subsection{Hydro Electric Power Generation}

Power generation is calculated by using the potential energy of stored water in reservoir, and it is given by [46]:

$$
P=\frac{Q * \rho * H * \eta * g}{1000}
$$

where

$P$ - the generated power in kVA

$Q$-water flow rate $\left(\mathrm{m}^{3} / \mathrm{s}\right)$

$\rho$-water density $\left(\mathrm{kg} / \mathrm{m}^{3}\right)$

$H$-height of waterfall (m)

$\eta$-the efficiency ratio (usually between 0.7 and 0.9 )

$\mathrm{g}$-acceleration due to gravity $\left(\mathrm{m} / \mathrm{s}^{2}\right)$

The maximum available energy generated within $24 \mathrm{~h}$ in (GWh) is given using the following formula:

$$
E=24 * \frac{P(k W)}{1000 * 1000}
$$

\subsection{Major Constraints and Limitations}

Although all the equations and constraints of IBMR are very large in number and not possible to mention here, few important constraints are given below:

$$
\begin{array}{r}
\text { Flow }(i, j, t)<\operatorname{Capacity}(i, j, t) \\
\operatorname{Flow}(i, j, t)>0 \\
\text { Family }(Z, G, M)<\operatorname{HumanResource}(Z, G) \\
\text { Family }(Z, G, M)>0 \\
\text { Export }(Z, C E)<\operatorname{Production}(Z, C E) \\
\text { Export }(Z, C E)>O \\
\text { CanalDiversion }(M)<\operatorname{Capacity}(M) \\
\text { CanalDiversion }(M)>0 \\
\text { Slakeland }(Z, G)<\text { LandRocources }(Z, G)_{\text {Slakeland }(Z, G)>0} \\
\text { Volume }_{m}<\operatorname{Rule}(U p, M) \\
\text { Volume }_{m}>\operatorname{Rule}(\text { Lo }, M)
\end{array}
$$

where $i$ and $j$ are indexes for node $i$ and $j, Z$ is the Agro climatic Zone (ACZ) index, $G$ is the groundwater type index, $C E$ refers to the commodity index and $M$ is the month 
index. These constraints are related to inflows in the canal, canal capacity, exports, canal diversions, slakeland and upper (Up) and lower (Lo) limits of volume in the reservoir.

Major constraints include the following:

1. Canal Commands: 42 canal commands are used to represent the whole irrigation system.

2. The Inter-Provincial Accord 1991: IRSA Rules are used for water allocation to the provinces.

3. Reservoir Operating Rule: Monthly lower and upper boundaries of reservoir capacity are used as upper and lower bounds. No complex, operating rules are defined for this purpose.

4. Turbine efficiency: $80 \%$ efficiency is used.

5. Only fifteen crops are the part of current IBMR.

6. Aquifer behavior is not considered in the modeling.

\section{Methods and Materials}

\subsection{Input Data}

The inputs to the IBMR-2020 include (1) livestock and agronomic data; (2) resources inventory; (3) economic data; and (4) canal commands and water inflows related data.

\subsection{Scenarios Development}

The following three scenarios have been designed and analyzed using proposed model:

1. Scenario1: Whole water is utilized for agriculture.

2. Scenario2: Whole water is utilized for power generation.

3. Scenario3: Water is utilized both for power generation and agricultural purposes.

\subsection{Study Area}

Different studies on the Indus basin have been performed considering upper [47] and lower Indus Basin [48]. In this study, we have included the Pakistan's site of the whole Indus basin. The Indus stream framework is comprised of the fundamental Indus River and its significant tributaries: The Jhelum, Kabul, Ravi, Sutlej and Chenab [49,50]. Pakistan's side of the Indus basin has been included for hydropower and agricultural purposes. The study area covers the all twelve Agro Climatic Zones (ACZ). The basin includes three major reservoirs namely Mangla, Tarbela and Warsak with live storage capacity of about 14 MAF, which accounts for about $10 \%$ of annual inflows. The system consists of the world's largest canal network with 42 major canals [51]. Figure 3 shows the Indus river and its tributaries, major reservoirs and barrages.

The Indus Basin covers 1,120,000 $\mathrm{km}^{2}$ of area, which is $54 \%$ of the South Asia. Area wise distribution of the Indus basin is given below Table 1:

Table 1. Indus Basin Country wise (Aquastat Survey 2011).

\begin{tabular}{llll}
\hline Country & Area $\left(\mathbf{k m}^{2} \mathbf{)}\right.$ & \% of Country & \% of Basin Area \\
\hline Pakistan & 520,000 & 47 & 65 \\
India & 440,000 & 39 & 14 \\
China & 88,000 & 8 & 10 \\
Afghanistan & 72,000 & 6 & 11 \\
\hline
\end{tabular}

\subsection{Water Resources Availability, Storage and Future Projects}

Pakistan has three mega dams with a total live capacity of around 11 MAF. At the moment, Pakistan is completely reliant on three western Indus tributaries, namely Kabul, Jhelum, and Chenab, whereas three eastern Indus tributaries Ravi, Sutlej, and Beas were granted to India for exclusive use following an agreement. Approximately 4.60 MAF of water flows from India to Pakistan through these eastern rivers, with an additional 3.33 MAF of run-off generated in Pakistan's catchments. The Kabul River contributes $21 \mathrm{MAF}$ to surface water. The Indus River System receives an average annual water inflow 
of roughly $146 \mathrm{MAF}$, according to IRSA data (2013), which is largely obtained from snow and glacier melting. Pakistan's present water availability at various canal headworks is at 97.71 MAF, with yearly losses projected to be around 48.29 MAF. Pakistan draws roughly $50 \mathrm{MAF}$ from groundwater aquifers and has already exceeded the safe yield limit. Salinisation and higher concentrations of fluorides and arsenic in water have resulted from over-mining and aquifer degradation, compromising the condition of agricultural areas [53]. Water availability in Pakistan is now less than 110 cubic meters per capita. Pakistan only has a 30-day water storage capacity [54]. Table 2 shows the proposed dams to overcome the water needs of the country.



Figure 3. The Indus Basin of Pakistan [52].

Table 2. Proposed future projects [55].

\begin{tabular}{lllll}
\hline Sr.No & Project & Live Capacity MAF & Installed Capacity MW & Expected Year of Completion \\
\hline 1 & Daimer Basha & 6.40 & 4500 & 2028 \\
2 & Mohmand Dam & 0.67 & 800 & 2025 \\
3 & Katzarah Dam & 35.00 & 15,000 & TBD \\
4 & Dasu Dam & 1.14 & 4320 & 2025 \\
5 & Banji Dam & 1.14 & 7100 & TBD \\
\hline
\end{tabular}

The proposed model is programmed in GAMS and dynamic nonlinear programming solver based on the generalized reduced gradient (GRG) method is used for CPS maximization calculation. The DNLP Solver has been used to solve the IBMR2022 nonlinear model. GRG uses the path of steepest ascent/descent. It moves from one feasible solution to another until the objective function value stops improving i.e., converges. The flow chart of the GRG method is shown in Figure 4. The real-time data for the Indus River System at rim stations of around 80 years old have been used. Different exceedance probabilities have been used for inflows calculation, and IRSA Rules for water distributions among the 
different provinces of Pakistan are used. Microsoft Excel and GAMS Studio have been used for calculations and optimizations.

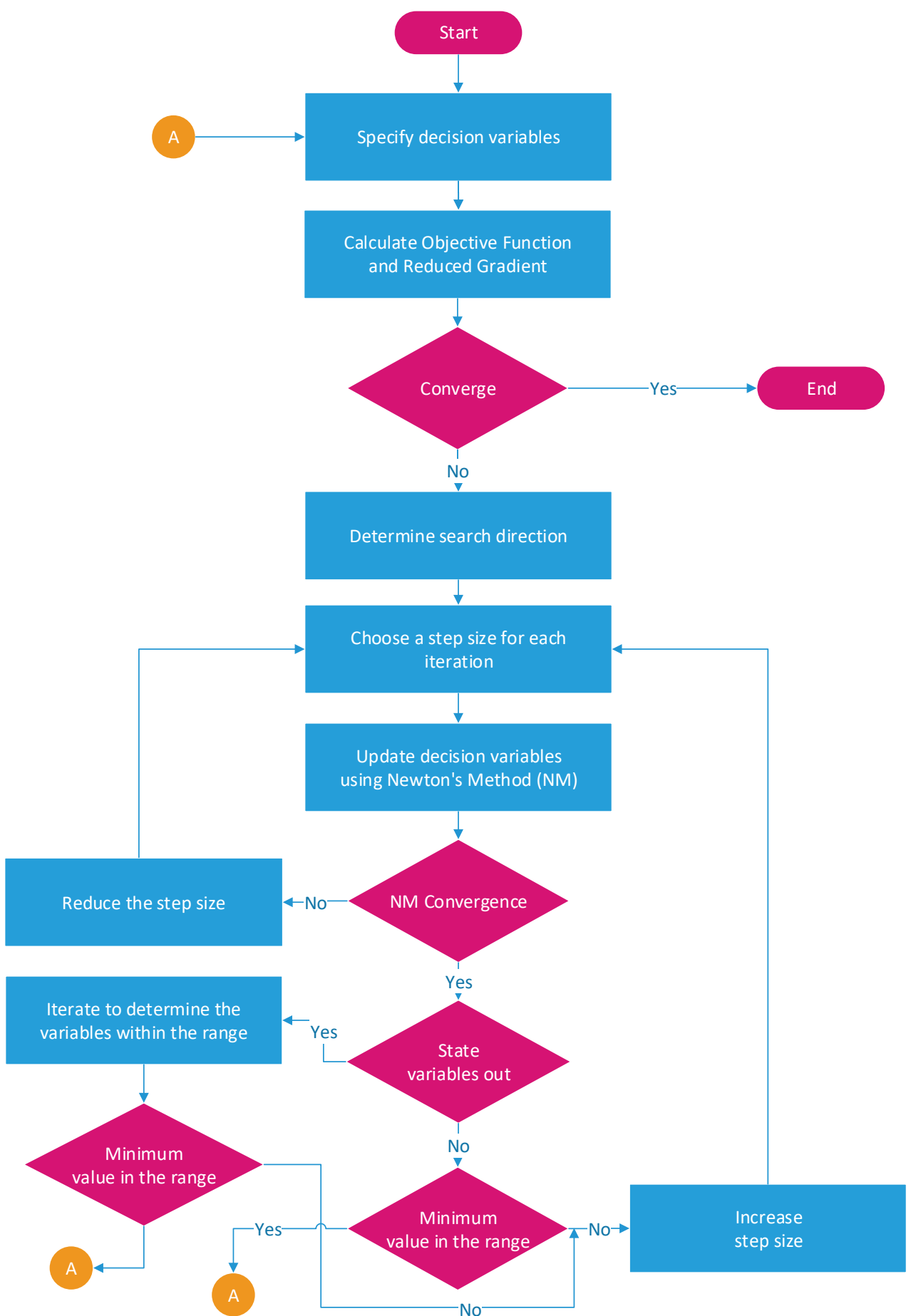

Figure 4. Flow chart of the generalized reduced gradient method [56].

\section{Results and Discussion}

This section contains case studies dealing with the analysis of the proposed scenarios, and their results with discussion.

\subsection{Scenario1}

Whole Water Is Utilized for Agriculture If the whole water is used for agriculture purposes, the net basin-wide economic benefit calculated by using IBMR-2021 is 33,605.85 
million dollars. This number is very close to economic benefits of agriculture income calculated using IBMR 2012.

\subsection{Scenario2: Whole Water Is Utilized for Power Generation}

If the whole water is used for electricity generation purposes, the net basin-wide economic benefit calculated by using IBMR-2021 is 9,567,606.66 million dollars. This number is very large and gives rise to a huge economic benefit apparently but is not practical because, if there is no agriculture, then there is no concept of life.

\subsection{Scenario3: Water Is Utilized Both for Agricultural Purposes and Power Generation}

The option to use water for both agriculture and power generation fulfills both food and power needs. This can be achieved using the parameter $\alpha$ introduced in Equation (2). If $50 \%$ water is used for agriculture and the remaining $50 \%$ is used for power generation, about 2.73 billion dollars in benefits is increased. Please note that all the calculations are performed using an updated Indus Basin Model Revised 2021 (IBMR-2021) with 50\% inflow exceedance probability.

\subsection{Impact of $\alpha$ on Agriculture and Power Generation}

The parameter $\alpha$ controls the usage of water for both agriculture and power generation in IBMR. The value of $\alpha=1$ means that the whole water is used for agriculture purposes, whereas the value of $\alpha=0$ shows the total water potential for hydropower generation. Figure 5 shows the impact of $\alpha$ on agriculture and power generation.

\section{Energy and Agricultural Benefits Comparison}

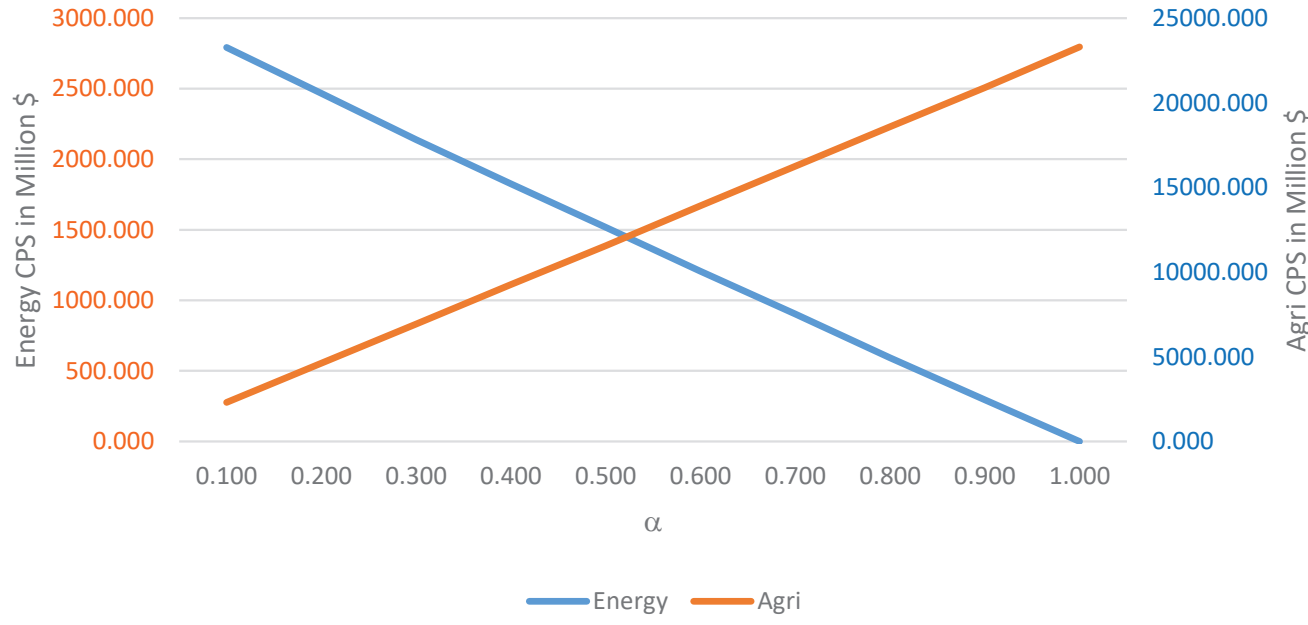

Figure 5. Impact of $\alpha$ on agriculture and energy.

From Figure 5 , it can be observed that $\alpha=0.5$ is the equilibrium point for both agriculture and energy monitory values. For $\alpha=0.1$, the maximum increase in CPS is around $11.83 \%$, and it gradually decreases with the increase of $\alpha$. When $\alpha$ is 0.9 , the minimum increase in CPS is $1.29 \%$, as shown in Table 3 . The results show that, the greater the water allocation for hydropower, the greater the economic benefit. The variation of CPS for different values of $\alpha$ is shown in Figure 5. 
Table 3. Impact of hydropower on basin wide income with $50 \%$ exceedance probability.

\begin{tabular}{lllll}
\hline $\boldsymbol{\alpha}$ & Energy Income Million \$ & Agri Income Million \$ & CPS Million \$ & \% Increase in CPS \\
\hline 0.10 & 2754.37 & $23,276.64$ & $26,031.02$ & 11.83 \\
0.20 & 2433.64 & $23,275.32$ & $25,708.96$ & 10.46 \\
0.30 & 2129.24 & $23,286.25$ & $25,415.50$ & 9.14 \\
0.40 & 1832.88 & $23,286.35$ & $25,119.22$ & 7.87 \\
0.50 & 1518.59 & $23,286.48$ & $24,805.07$ & 6.52 \\
0.60 & 1208.64 & $23,286.97$ & $24,495.61$ & 5.19 \\
0.70 & 905.62 & $23,287.43$ & $24,193.06$ & 3.89 \\
0.80 & 603.34 & $23,277.71$ & $23,881.05$ & 2.59 \\
0.90 & 301.09 & $23,287.53$ & $23,588.62$ & 1.29 \\
\hline
\end{tabular}

\subsection{Impact of Hydropower on Basin Wide Income}

Using the proposed formulation for CPS and hydropower generation, basin wide income (CPS) has been calculated using the IBMR-2021 model. Results are shown in the Tables 3 and 4: Please note that we have used $50 \%$ and $80 \%$ exceedance probabilities for these calculations. It is observed that basin wide income increases by about $11.83 \%$ with the inclusion of power generation in CPS. For details, please see the Tables 3 and 4 .

Table 4. Impact of hydropower on basin wide income with $80 \%$ exceedance probability.

\begin{tabular}{lllll}
\hline $\boldsymbol{\alpha}$ & Energy Income Million \$ & Agri Income Million \$ & CPS Million \$ & \% Increase in CPS \\
\hline 0.10 & 1930.95 & $21,672.34$ & $23,603.29$ & 8.91 \\
0.20 & 1716.24 & $21,683.27$ & $23,399.51$ & 7.92 \\
0.30 & 1501.60 & $21,627.22$ & $23,128.82$ & 6.94 \\
0.40 & 1286.28 & $21,672.42$ & $22,958.69$ & 5.94 \\
0.50 & 1071.89 & $21,683.33$ & $22,755.23$ & 4.94 \\
0.60 & 857.46 & $21,681.80$ & $22,539.26$ & 3.95 \\
0.70 & 642.82 & $21,628.84$ & $22,271.66$ & 2.97 \\
0.80 & 427.75 & $21,681.90$ & $22,109.65$ & 1.97 \\
0.90 & 213.05 & $21,560.62$ & $21,773.66$ & 0.99 \\
\hline
\end{tabular}

\subsection{Cost Comparison of Hydro Energy with Other Energy Sources}

Table 5 shows price comparison among different sources of energy. From the table, it is evident that hydropower has the lowest Per Kilowatt Hour cost as compared to other sources.

Table 5. Cost comparison of hydro energy with other energy sources $[57,58]$.

\begin{tabular}{lll}
\hline Sr. No & Type of Energy & Cost of Per Kilowatt Hour in \$ \\
\hline 1 & Hydro Electric Power & 0.01 \\
2 & Coal-fired Power & 0.08 \\
3 & Furnace Oil-based Electricity & 0.11 \\
4 & Wind Power & 0.07 \\
5 & Solar Electricity & 0.13 \\
\hline
\end{tabular}

\subsection{Pakistan's Water Budget and Associated Problem}

Figure 6 depicts Pakistan's water budget and associated problems i.e., the mean annual River inflows (140 MAF), flows to Arabian (27 MAF), total water available water $(140+50+$ $13=203 \mathrm{MAF})$, total losses $(10+26+23+10+24+27=120)$, total available water for crops consumption is 83 MAF. Thus, the total available water for agricultural use is about $40.89 \%$ 
and total losses are 59.11\% [59]. Therefore, it is recommended to take necessary actions for infrastructure maintenance to avoid this large amount of loss and increase productivity.

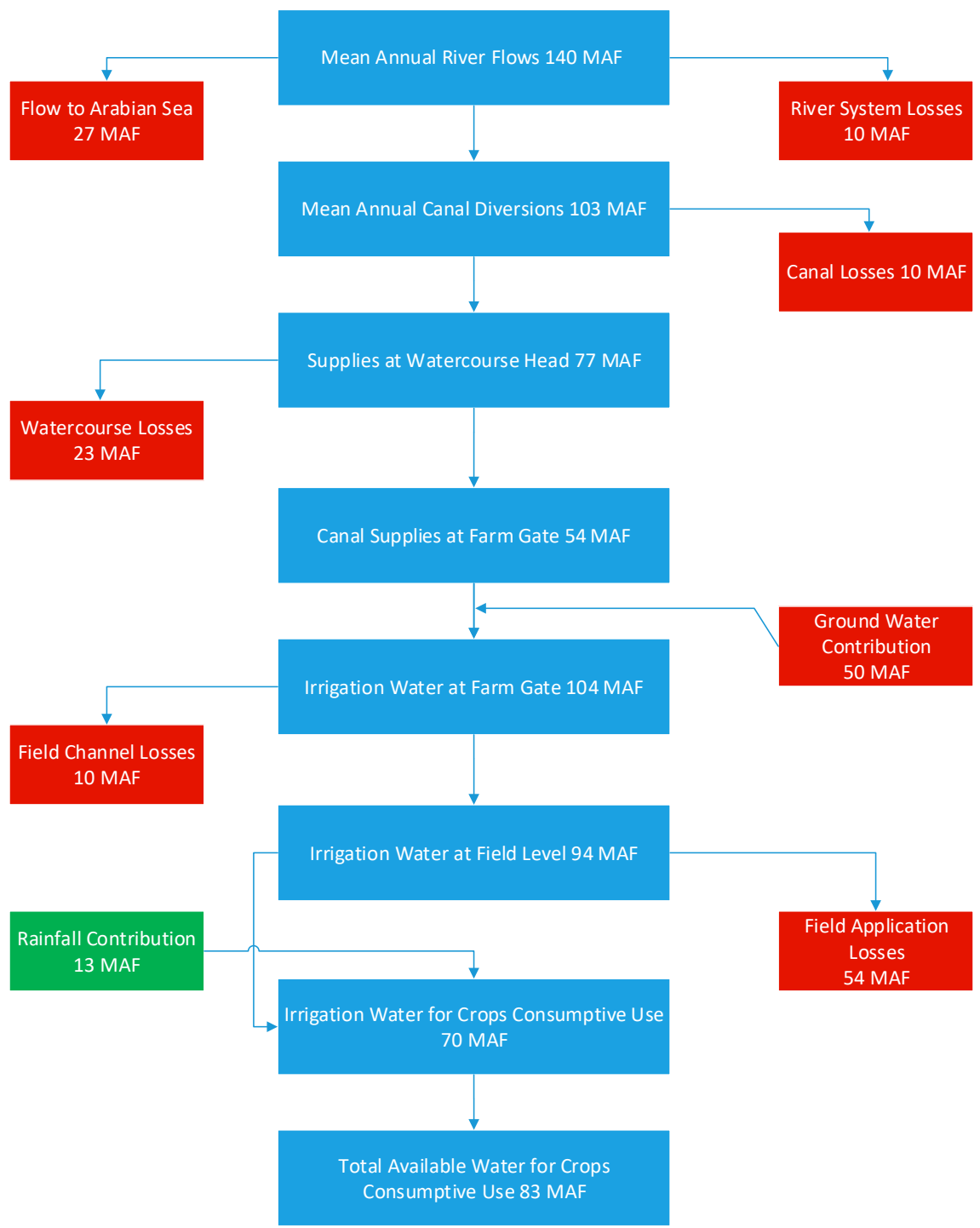

Figure 6. Pakistan's water budget and associated problem.

\subsection{Output Data}

The outputs from the proposed IBMR are of great importance for policymakers and researchers. It provides a great insight to policymakers for future planning in the field of agriculture and hydropower generation. The main objective function provides the basin-wide income and net profit from agricultural production and power generation. It also provides the value of water stored in reservoirs, agricultural imports and exports, the economic benefits, and the flow of water to the sea.

\subsection{Pakistan's Energy Mix by the Year 2040}

The energy mix composition calculated by the proposed IBMR model is shown in Figure 7. The pie chart shows that the hydro power will take a major share of about $40 \%$ followed by $25 \%$ local coal and renewable being the third largest contributor of about $16 \%$. By 2040 , we would have around $56 \%$ of the hydro and renewable energy share in accordance with the SDG 7 initiative by the government of Pakistan. The obtained results are in close agreement with results given in the indicative generation plan 2040 by NTDC. This indicates the promise of the approach. 
Pakistan's Energy Mix by year 2040


Figure 7. Pakistan's energy mix by 2040.

5.10. Indicative Generation Plan for the Year 2040

An exponential model has been derived using the data from NTDC to obtain a yearly indicative generation plan. Table 6 shows the comparison between the Indicative Generation Plan for the year 2040 by NTDC [21] and that calculated using the proposed IBMR2021. The estimated values from both NTDC and IBMR-2021 are 370,348.00 GWh and $367,549.84 \mathrm{GWh}$, respectively, and in good agreement with the reference energy estimated by NTDC.

Table 6. Indicative Generation Plan for the year 2040.

\begin{tabular}{lll}
\hline Year & NTDC Energy Estimated (GWh) & IBMR Energy Estimated (GWh) \\
\hline $2020-21$ & $158,842.00$ & $154,540.92$ \\
$2021-22$ & $166,267.00$ & $161,751.13$ \\
$2022-23$ & $173,178.00$ & $169,297.74$ \\
$2023-24$ & $181,051.00$ & $177,196.44$ \\
$2024-25$ & $188,749.00$ & $185,463.65$ \\
$2025-26$ & $193,948.00$ & $194,116.58$ \\
$2026-27$ & $202,763.00$ & $203,173.22$ \\
$2027-28$ & $211,718.00$ & $212,652.40$ \\
$2028-29$ & $220,940.00$ & $222,573.84$ \\
$2029-30$ & $231,142.00$ & $232,958.17$ \\
$2030-31$ & $241,889.00$ & $243,826.99$ \\
$2031-32$ & $253,101.00$ & $255,202.90$ \\
$2032-33$ & $265,289.00$ & $267,109.56$ \\
$2033-34$ & $278,069.00$ & $279,571.74$ \\
$2034-35$ & $291,403.00$ & $292,615.34$ \\
$2035-36$ & $305,685.00$ & $306,267.51$ \\
$2036-37$ & $320,652.00$ & $320,556.62$ \\
$2037-38$ & $336,293.00$ & $335,512.40$ \\
$2038-39$ & $352,917.00$ & $351,165.96$ \\
$2039-40$ & $370,348.00$ & $367,549.84$ \\
\hline
\end{tabular}

\subsection{Government Initiatives under SDG 7 for Hydropower Generation}

Maintaining uninterrupted energy sources needs a high level of energy integration. Pakistan's renewable energy policy is being improved in order to attract investment in a safe, renewable, and affordable energy mix. In order to reduce gas shortages, the country is also looking for ways to tap into its unconventional gas resource potential.

Table 7 shows the hydropower projects under construction and their expected time of completion, $\$ / \mathrm{kw}$ cost and generation capacity. 
Table 7. Government initiatives under SDG 7 for hydropower generation.

\begin{tabular}{llllll}
\hline Power Plant & Capacity (MW) & Year & Installed Cost (\$/KW) & Annual Energy (GWh) & Cost (c/KWh) \\
\hline Matiltan & 84 & 2020 & 2457 & 339 & 6.38 \\
Lawi & 69 & 2021 & 2854 & 311 & 6.61 \\
Laut HPP & 49 & 2021 & 3202 & 205 & 7.96 \\
Harigel & 40 & 2022 & 2697 & 223 & 5.06 \\
Jagran-II & 35 & 2022 & 2068 & 154 & 4.97 \\
Dasu Hydel & 2160 & 2023 & 1888 & 11,176 & 3.87 \\
Gumat Nar & 49.5 & 2023 & 3253 & 218 & 7.68 \\
Harpo & 34.5 & 2024 & 2947 & 173 & 6.13 \\
Lower Palas & 665 & 2024 & 1901 & 2568 & 5.22 \\
Lower SpatGah & 496 & 2024 & 2060 & 2084 & 5.18 \\
Phander & 80 & 2024 & 1824 & 365 & 4.25 \\
Mohmand dam & 800 & 2024 & 2244 & 2859 & 6.61 \\
Ashkot HPP & 300 & 2024 & 2301 & 1376 & 5.28 \\
Tarbela5 & 1410 & 2025 & 586 & 1401 & 6.95 \\
Pattan & 2400 & 2026 & 1904 & 12,544 & 3.87 \\
Kohala & 1124 & 2028 & 2456 & 6608 & 4.38 \\
Azad Pattan & 700 & 2028 & 2164 & 3192 & 5.01 \\
Thakot HPP & 4000 & 2028 & 3205 & 19,947 & 6.68 \\
Shyok HPP & 640 & 2028 & 2793 & 3740 & 4.99 \\
Diamer Basha & 4500 & 2029 & 1711 & 18,071 & 5.00 \\
Chakothi & 500 & 2029 & 2353 & 2440 & 5.07 \\
Mhl & 640 & 2030 & 2266 & 3720 & 4.10 \\
Bunji Hydel & 3600 & 2030 & 1901 & 12,078 & 6.00 \\
\hline
\end{tabular}

\section{Conclusions}

This paper presents the modified IBMR-2021 dealing optimal usage of water for both agriculture and electrical power generation. This model is a valuable addition for both IRSA and NTDC and supports government commitment towards SDG. The main objective function of IBMR-2012 that calculates CPS has been modified to incorporate the optimal share of water for electrical power generation. In the current research, an enhanced version of IBMR has been proposed which accounts for hydropower generation along with agriculture. The aim was to study the impact of hydropower on basin wide income by incorporating hydropower generation in IBMR modified version. The following three cases studies have been analyzed, and results are presented. The current research broadens the use of IBMR not only for agriculture but also for hydropower generation and planning, aiming to reduce the energy costs and effective utilization of water:

- Scenario1: Currently, the IBMR accounts for this scenario, i.e., the whole water is used for agriculture and basin wide income is purely rely on agriculture income.

- Scenario2: Explains an extreme scenario when all of the water is utilized for hydropower. In this case, the net basin income goes very high, but practically we cannot spare all of the water for hydropower.

- Scenario3: This scenario covers both agriculture and hydropower generation income simultaneously in one objective function. If $50 \%$ water is allocated for agriculture and the rest of the $50 \%$ for power generation, about 2.73 billion dollars in benefit is increased.

The analysis of these case studies show that basin-wide income increases by $11.83 \%$ using $50 \%$ exceedance probability with the inclusion of power generation. The results are in agreement with reference to power generation estimated by NTDC. Green energy due to technological breakthroughs has gained a lot of attention and provides cost-effective solutions for power needs. The Government initiatives for a hydropower project and NTDC year 2040 plan both emphasize hydropower, which is clean and affordable energy. Hence, 
pushing for and ensuring delivery of SDG 7 in full letter and spirit. In order to exploit the hydropower potential of the Indus River System, the incorporation of the hydrothermal coordination aspect in this modified version could be another exciting and innovative dimension for future work. Traditionally, IBMR has been used by WAPDA and other policy makers for agriculture and irrigation related planning.

\section{Future Recommendations}

The following studies are recommended to further explore the potential of various areas of research in the Indus Basin:

i. More crops like olives need to be added in the model as it is one of the fastest growing crops in the region and will add revenue in the basin income.

ii. Aquifer behavior needs to be considered for more accurate modeling on under water storage.

iii. Hydro and other renewable energy sources coordination at the basin level could be a good idea for future research. To reduce the overall fuel generation cost, the best combination for generation using different sources needs to be investigated.

iv. Climate change scenarios like Representative Concentration Pathways need to be investigated for both the upper and lower Indus basin.

Author Contributions: A.H. and A.I.B. conceived of the presented idea. A.H. and A.I.B. developed the theory and performed the computations. S.A., A.S. and M.A.U.R.T. verified the analytical methods. S.A. and A.I.B. encouraged A.H. to investigate hydropower impact on Indus Basin Income and supervised the findings of this work. All authors have read and agreed to the published version of the manuscript.

Funding: This research received no external funding.

Institutional Review Board Statement: Not applicable.

Informed Consent Statement: Not applicable.

Data Availability Statement: Not applicable.

Acknowledgments: We would like to thank Muhammad Mansoor Ahmed for providing an opportunity to pursue my PhD at CUST. Special thanks to Salis Usman (GM at NTDC) for providing necessary data. We would like to thank Nadeem Shaukat (Center for Mathematical Sciences, PIEAS) for his valuable discussion throughout the work. Special thanks to Majid Ali from CUST and Tahir Nadeem Malik from HITEC University, for their valuable discussion throughout the research. Last but not the least, we would like to thank the very kind and humble Shahbaz Khan (Regional director UNESCO, China) for his unconditional support and guidance.

Conflicts of Interest: The authors declare no conflict of interest.

\section{Abbreviations}

The following abbreviations are used in this manuscript:

$\begin{array}{ll}\alpha & \text { Control Parameter } \\ \text { ACZ } & \text { Agroclimatic Zone } \\ \text { AEDB } & \text { Alternative Energy Development Board } \\ \text { AIS } & \text { Agricultural Impact Study } \\ \text { CPS } & \text { Consumer Producer Surplus } \\ \text { DNLP } & \text { Discontinuous Nonlinear Program } \\ \text { GAMS } & \text { General Algebraic Modeling System } \\ \text { GRG } & \text { Generalized Reduced Gradient } \\ \text { HBV } & \text { Hydrologiska Byråns Vattenbalansavdelning } \\ \text { IBMR } & \text { Indus Basin Model Revised } \\ \text { IRSA } & \text { Indus River System Authority } \\ \text { IWRM } & \text { Integrated Water Resources Management } \\ \text { MAF } & \text { Million Acre Feet }\end{array}$




$\begin{array}{ll}\text { MDG } & \text { Millennium Development Goals } \\ \text { NTDC } & \text { Nation Transmission and Distribution Company } \\ \text { NEECA } & \text { National Energy Efficiency and Conservation Authority } \\ \text { RCP } & \text { Representative Concentration Pathway } \\ \text { SDG } & \text { Sustainable Development Goals } \\ \text { SHP } & \text { Small Hydropower Plants } \\ \text { TAPI } & \text { Turkmenistan Afghanistan Pakistan-India } \\ \text { TWh } & \text { Tera Watt-hours } \\ \text { TBD } & \text { To Be Decided } \\ \text { WAPDA } & \text { Water and Power Development Authority }\end{array}$

\section{References}

1. Hunt, J.D.; Falchetta, G.; Parkinson, S.; Vinca, A.; Zakeri, B.; Byers, E.; Jurasz, J.; Quaranta, E.; Grenier, E.; Junior, A.O.P.; et al. Hydropower and seasonal pumped hydropower storage in the Indus basin: Pros and cons. J. Energy Storage 2021, $41,102916$. [CrossRef]

2. Kuriqi, A.; Pinheiro, A.N.; Sordo-Ward, A.; Garrote, L. Water-energy-ecosystem nexus: Balancing competing interests at a run-of-river hydropower plant coupling a hydrologic-ecohydraulic approach. Energy Convers. Manag. 2020, $223,113267$. [CrossRef]

3. Dhaubanjar, S.; Lutz, A.F.; Gernaat, D.; Nepal, S.; Pradhananga, S.; Khanal, S.; Bhakta Shrestha, A.; Immerzeel, W. Quanitification of sustainable hydropower potential in the Upper Indus basin. In Proceedings of the EGU General Assembly Conference Abstracts, Virtuel Event, 19-30 April 2021.

4. Immerzeel, W.W.; Lutz, A.; Andrade, M.; Bahl, A.; Biemans, H.; Bolch, T.; Hyde, S.; Brumby, S.; Davies, B.; Elmore, A.; et al Importance and vulnerability of the world's water towers. Nature 2020, 577, 364-369. [CrossRef]

5. Smolenaars, W.J.; Lutz, A.F.; Biemans, H.; Dhaubanjar, S.; Immerzeel, W.W.; Ludwig, F. From narratives to numbers; spatial downscaling and quantification of future water, food \& energy security requirements in the Indus basin. Futures 2021, $133,102831$.

6. Kiani, R.S.; Ali, S.; Ashfaq, M.; Khan, F.; Muhammad, S.; Reboita, M.S.; Farooqi, A. Hydrological projections over the Upper Indus Basin at $1.5^{\circ} \mathrm{C}$ and $2.0^{\circ} \mathrm{C}$ temperature increase. Sci. Total Environ. 2021, 788, 147759. [CrossRef] [PubMed]

7. Frenken; Karen. Irrigation in Southern and Eastern Asia in Figures: AQUASTAT Survey-2011; Water Reports; FAO: Rome, Italy, 2012.

8. Bank, W. Indus Water Treaty; Ministry of External Affairs, Government of India: New Delhi, India, 1960; pp. 99-101.

9. Anwar, A.A.; Bhatti, M.T. Pakistan's water apportionment Accord of 1991: 25 years and beyond. J. Water Resour. Plan. Manag. 2018, 144, 05017015. [CrossRef]

10. Ahmad, M.; Kutcher, G.P. Irrigation Planning with Environmental Considerations: A Case Study of Pakistan's Indus Basin; The World Bank: Washington, DC, USA, 1992.

11. Bisschop, J.; Candler, W.; Duloy, J.H.; O’Mara, G.T. The indus basin model: A special application of two-level linear programming. In Applications; Springer: Berlin/Heidelberg, Germany, 1982; pp. 30-38.

12. Candler, W.; Norton, R. Multi-Level Programming and Development Policy; The World Bank: Washington, DC, USA, 1977.

13. O'Mara, G.T.; Duloy, J.H. Modeling efficient water allocation in a conjunctive use regime: The Indus Basin of Pakistan. Water Resour. Res. 1984, 20, 1489-1498. [CrossRef]

14. Ahmad, M.; Kutcher, G.; Meeraus, A. The Agricultural Impact of the Kalabagh Dam (as Simulated by the Indus Basin Model Revised ); World Bank: Washington, DC, USA, 1986; Volumes I and II

15. Chaudhry, M.T.; Labadie, J.W.; Hall, W.A.; Albertson, M.L. Optimal conjunctive use model for Indus Basin. J. Hydraul. Div. 1974, 100, 667-687. [CrossRef]

16. Ahmad, M.; Brooke, A.; Kutcher, G.P. Guide to the Indus Basin Model Revised; World Bank: Washington, DC, USA, 1990.

17. Cherfas, J.; Langan, S.; Leb, C.; Newton, J.; Nicol, A.; Shrestha, A. Managing Systems under Stress: Science for Solutions in the Indus Basin. In Proceedings of the 3rd Indus Basin Knowledge Forum (IBKF), Laxenburg, Austria, 31 May-2 June 2018.

18. Wescoat, J.L., Jr.; Halvorson, S.J.; Mustafa, D. Water management in the Indus basin of Pakistan: A half-century perspective. Int. J. Water Resour. Dev. 2000, 16, 391-406. [CrossRef]

19. Stewart, J.; Podger, G.; Ahmad, M.; Shah, M.; Bodla, H.; Khero, Z.; Rana, M. Indus River System Model (IRSM)—A Planning Tool to Explore Water Management Options in Pakistan: Model Conceptualisation, Configuration and Calibration; Technical Report; South Asia Sustainable Development Investment: St Lucia, Australia, 2018.

20. Pakistan Energy Yearbook 2017; Hydrocarbon Development Institute of Pakistan : Islamabad, Pakistan, 2017.

21. Usman, S.; Razzaq, A. Indicative Generation Capacity Expansion Plan 2018-2040. Available online: https://nepra.org.pk/ Admission\%20Notices /2019/09-September/IGCEP\%20Plan\%20(2018-40).pdf (accessed on 1 November 2021 ).

22. Tahir, Z.U.R.; Kanwal, A.; Afzal, S.; Ali, S.; Hayat, N.; Abdullah, M.; Saeed, U.B. Wind Energy Potential and Economic Assessment of Southeast of Pakistan. Int. J. Green Energy 2020, 18, 1-16. [CrossRef]

23. Khaliq, A.; Ikram, A.; Salman, M. Quaid-e-Azam solar power park: Prospects and challenges. In Proceedings of the 2015 Power Generation System and Renewable Energy Technologies (PGSRET), Islamabad, Pakistan, 10-11 June 2015; pp. 1-6.

24. Asif, M. Sustainable energy options for Pakistan. Renew. Sustain. Energy Rev. 2009, 13, 903-909. [CrossRef] 
25. Zeshan, M. Finding the cointegration and causal linkages between the electricity production and economic growth in Pakistan. Econ. Model. 2013, 31, 344-350. [CrossRef]

26. Rafique, M.M.; Rehman, S. National energy scenario of Pakistan-Current status, future alternatives, and institutional infrastructure: An overview. Renew. Sustain. Energy Rev. 2017, 69, 156-167. [CrossRef]

27. Sheikh, M.A. Energy and renewable energy scenario of Pakistan. Renew. Sustain. Energy Rev. 2010, 14, 354-363. [CrossRef]

28. Farooq, M.K.; Kumar, S. An assessment of renewable energy potential for electricity generation in Pakistan. Renew. Sustain. Energy Rev. 2013, 20, 240-254. [CrossRef]

29. Rehman, A.; Zhang, D.; Chandio, A.A.; Irfan, M. Does electricity production from different sources in Pakistan have dominant contribution to economic growth? Empirical evidence from long-run and short-run analysis. Electr. J. 2020, 33, 106717. [CrossRef]

30. Revenga, C.; Tyrrell, T. Major river basins of the world. In The Wetland Book; II: Distribution, Description and Conservation; Springer: Berlin/Heidelberg, Germany, 2016; pp. 1-16.

31. Lakshmi, V.; Fayne, J.; Bolten, J. A comparative study of available water in the major river basins of the world. J. Hydrol. 2018, 567, 510-532. [CrossRef]

32. Wolf, A.T.; Natharius, J.A.; Danielson, J.J.; Ward, B.S.; Pender, J.K. International river basins of the world. Int. J. Water Resour. Dev. 1999, 15, 387-427. [CrossRef]

33. Ward, S.; Scott Borden, D.; Kabo-bah, A.; Fatawu, A.N.; Mwinkom, X.F. Water resources data, models and decisions: International expert opinion on knowledge management for an uncertain but resilient future. J. Hydroinform. 2019, 21, 32-44. [CrossRef]

34. Dhaubanjar, S.; Lutz, A.F.; Gernaat, D.E.; Nepal, S.; Smolenaars, W.; Pradhananga, S.; Biemans, H.; Ludwig, F.; Shrestha, A.B.; Immerzeel, W.W. A systematic framework for the assessment of sustainable hydropower potential in a river basin-The case of the upper Indus. Sci. Total Environ. 2021, 786, 147142. [CrossRef]

35. Hairan, M.H.; Jamil, N.R.; Looi, L.J.; Azmai, M.N.A. The assessment of environmental flow status in Southeast Asian Rivers: A review. J. Clean. Prod. 2021, 295, 126411. [CrossRef]

36. Shirsat, T.S.; Kulkarni, A.V.; Momblanch, A.; Randhawa, S.; Holman, I.P. Towards climate-adaptive development of small hydropower projects in Himalaya: A multi-model assessment in upper Beas basin. J. Hydrol. Reg. Stud. 2021, 34, 100797. [CrossRef]

37. Grover, S.; Tayal, S.; Sharma, R.; Beldring, S. Effect of changes in climate variables on hydrological regime of Chenab basin, western Himalaya. J. Water Clim. Chang. 2021, 13, 357-371. [CrossRef]

38. Kahlown, M.A.; Majeed, A. Water-resources situation in Pakistan: Challenges and future strategies. In Water Resources in the South: Present Scenario and Future Prospects; Commission on Science and Technology for Sustainable Development in the South: Islamabad, Pakistan, 2003; Volume 20, pp. 33-45.

39. Tabassum, S. The Indus Basin is indispensable: An agro-hydropower dependency of India and Pakistan. J. Political Stud. 2018, 25, 257-269.

40. Dinar, A.; De Stefano, L.; Nigatu, G.; Zawahri, N. Why are there so few basin-wide treaties? Economics and politics of coalition formation in multilateral international river basins. Water Int. 2019, 44, 463-485. [CrossRef]

41. Briscoe, J.; Qamar, U.; Contijoch, M.; Amir, P.; Blackmore, D. Pakistan's Water Economy: Running Dry; World Bank: Washington, DC, USA, 2005.

42. Yang, Y.C.E.; Brown, C.M.; Yu, W.H.; Savitsky, A. An introduction to the IBMR, a hydro-economic model for climate change impact assessment in Pakistan's Indus River basin. Water Int. 2013, 38, 632-650. [CrossRef]

43. Janjua, S.; Hassan, I.; Muhammad, S.; Ahmed, S.; Afzaal, M. Water management in Pakistan's Indus Basin: Challenges and opportunities. Water Policy 2021, 23, 1329-1343. [CrossRef]

44. Colglazier, W. Sustainable development agenda: 2030. Science 2015, 349, 1048-1050. [CrossRef]

45. Pakistan's Implementation of the 2030 Agenda for Sustainable Development: Voluntary National Review. 2017. Available online: https://sustainabledevelopment.un.org/content/documents/233812019_06_15_VNR_2019_Pakistan_latest_version.pdf (accessed on 11 February 2021).

46. El-Aziz, T.M.A.; El-Aziz, N.M.A. Characteristic equations for hydropower stations of main barrages in Egypt. In Proceedings of the Eleventh International Water Technology Conference, IWTC11, Sharm El-Sheikh, Egypt, $15-18$ March 2007.

47. Archer, D. Contrasting hydrological regimes in the upper Indus Basin. J. Hydrol. 2003, 274, 198-210. [CrossRef]

48. Williams, M. Stratigraphy of the Lower Indus Basin, West Pakistan. In Proceedings of the 5th World Petroleum Congress, New York, NY, USA, 30 May 1959.

49. Chaudhry, S.A. Pakistan: Indus Basin Water Strategy-Past, Present and Future. Lahore J. Econ. 2010, 15, 187-211. [CrossRef]

50. Karimi, P.; Bastiaanssen, W.; Molden, D.; Cheema, M. Basin-wide water accounting using remote sensing data: The case of transboundary Indus Basin. Hydrol. Earth Syst. Sci. Discuss. 2012, 9, 12921-12958.

51. Shah, S.J. Maximum Water Storage Capacity in Various Dams Is 14 MAF. 2018. Available online: https://fp.brecorder.com/2018 /05/20180522373437/ (accessed on 15 November 2021).

52. Tamaddun, K.A.; Ahmed, W.; Burian, S.; Kalra, A.; Ahmad, S. Reservoir Regulations of the Indus River Basin under Different Flow Conditions. In World Environmental and Water Resources Congress 2018: Watershed Management, Irrigation and Drainage, and Water Resources Planning and Management; American Society of Civil Engineers Reston: Reston, VA, USA, 2018 ; pp. $207-219$.

53. WATER. 2014. Available online: https://www.pc.gov.pk/uploads/plans/Ch20-Water1.pdf (accessed on 15 January 2021). 
54. Pakistan Vision 2025—Planning Commission. 2013. Available online: https://www.pc.gov.pk/uploads/vision2025/PakistanVision-2025.pdf (accessed on 1 January 2022).

55. WAPDA. Water Resources. Available online: http://www.wapda.gov.pk (accessed on 15 December 2021).

56. Sakhaei, Z.; Azin, R.; Osfouri, S. Assessment of empirical/theoretical relative permeability correlations for gas-oil/condensate systems. In Proceedings of the 1st Biennial Persian Gulf Oil, Gas and Petrochemical Energy and Environment Conference, Bushehr, Iran, 20 April 2016; Volume 20.

57. Fatima, U.; Nasim, A. Cost of Electricity Generation in Pakistan-Comparison of Levelized Cost of Electricity of CPEC Coal Plants with Oil and Natural Gas Based Plants Commissioned in 2010-2014; Institute of Development and Economic Alternatives: Lahore, Pakistan, 2019.

58. Nasim, A.; Fatima, U. Cost of Electricity Generation in Pakistan-Comparison of Coal Plants with Oil and Natural Gas Based Plants; Technical Report; Institute of Development and Economic Alternatives: Islamabad, Pakistan, 2020.

59. Ahmad, S.; Majeed, R. Indus basin irrigation system water budget and associated problems. J. Eng. Appl. Sci. 2001, $20,69-77$. 